Article

\title{
Dual Frequency Orbiter-Radar System for the Observation of Seas and Tides on Titan: Extraterrestrial Oceanography from Satellite
}

\author{
Marco Mastrogiuseppe \\ Division of Geological and Planetary Sciences, California Institute of Technology, Pasadena, CA 91125, USA; \\ mmastrog@caltech.edu; Tel.: +1-626-628-6899
}

Received: 16 July 2019; Accepted: 6 August 2019; Published: 14 August 2019

check for updates

\begin{abstract}
Saturn's largest moon, Titan, is believed to have a 100 km thick ice shell above a global ocean of liquid water. Organic materials, including liquid hydrocarbon lakes and seas in its polar terrain, cover Titan's surface, which makes it a world of two oceans. The RADAR instrument on board Cassini, was able to probe lakes and seas during few dedicated altimetric observations, revealing its capability to work as a sounder. Herein, we describe the design of, and scientific motivation for, a dual frequency X/Ka-band radar system that is able to investigate Titan's subsurface liquid water ocean, as well as the depth and composition of its surface liquid hydrocarbon basins. The proposed system, which could take advantage of the telecommunications dish, can operate as a sounder, as Synthetic Aperture Radar (SAR) able to map the surface at tens meters of scale resolution, and when data are acquired from close-adjacent orbits, as a repeat-pass SAR interferometer (InSAR). The instrument, which is based on the architecture of the Cassini RADAR, can also characterize Titan's interior by using geophysical measurements of the tidal amplitude to derive high accuracy estimates of the Love number h2 from a $1500 \mathrm{~km}$ circular orbit.
\end{abstract}

Keywords: bathymetry; radar system; extraterrestrial oceanography; geophysical measurements

\section{Introduction}

Titan, the second largest moon in our solar system, has been repeatedly observed by the Cassini spacecraft during its 13 years exploration of the Saturnian system (2004-2017). The Cassini RADAR instrument was capable of operating in multimode as a Synthetic Aperture Radar (SAR) for surface imaging, as a radar altimeter for topography measurements, as a scatterometer for surface composition and, in passive mode, as a radiometer for brightness temperature [1]. The instrument has provided imaging at $300 \mathrm{~m} /$ pixel for about $20 \%$ of the surface of the moon and $\sim 50 \%$ has been mapped at $1500 \mathrm{~m} /$ pixels, as well as 40 topographic profiles have been acquired in altimetry mode. This dataset enabled the identification and characterization of several geomorphologic features.

Hundred meters high dunes fields [2], which are spread across the equator $\left( \pm 30^{\circ}\right.$ in latitude), covering about $15 \%$ of the whole surface [3,4] have been observed by the instruments in different modes (i.e., SAR, altimetry, radiometry). Their shape is believed to be the result of a general eastward transport of cohesive organic solids [5], their morphology being similar to the terrestrial dunes seen in Namib, Sahara, and Arabian deserts [6], and their material is likely to be composed by solid hydrocarbons, mixed with water ice at interdune [7-10]. Instruments on board Cassini also revealed the presence of mountains [11-13], craters [14] with possible cryovolcanic origin [15], in addition to a complex hydrological system that is made of liquid hydrocarbons with possible subsurface connection [16]. Other features, interpreted as empty lakes, have been mapped by Cassini and have been object of several works [17-19]. Their formation is still the object of studies, although some hypothesis regarding their endogenic origin has been recently proposed [20]. 
The presence of standing hydrocarbons liquid bodies on Titan was revealed by Cassini on 22 July 2006, during the fly-by T16, when the radar mapped a collection of 10-100 km diameter lakes present in the northern hemisphere [21]. Later observations revealed the existence of an active hydrological cycle of methane [22], and the presence of large northern basins identified as seas, or maria: Kraken Mare, Ligeia Mare and Punga Mare [23]. A detailed description and mapping of the Titan's polar terrains is reported in [24]. Specific observations that were planned and executed over the major seas and lakes in altimetry mode, made the direct measurements of depth-bathymetry and composition of few hydrocarbon basins present on Titan possible [25-27], revealing the ability of Cassini to work as a radar sounder despite the relative high operative frequency $(13.7 \mathrm{GHz})$. The same observations were also used to constrain the roughness of seas and lakes on Titan from surface amplitude analysis returns [27-30] and to detect the presence of fluvial networks of channels and canyons filled with liquid hydrocarbons [31].

Here, we propose a radar system that is able to provide three-dimensional high resolution bathymetric maps of Titan seas and lakes at multiple frequencies, allowing for the investigation of any possible spatial $[32,33]$ or seasonal [34] variation in composition of the liquid and/or sea floor properties. The system will additionally enable the investigation of any suspended particulates-material, density heterogeneities of the liquid column within a resolution of few meters. The use of an $\mathrm{X}$ band frequency could permit the detection of the seafloor of the largest Titan's sea, Kraken Mare, which is either too deep or too absorptive for being detected by the Cassini RADAR. Moreover, the radar system used in off-nadir configuration can provide high resolution mapping and, when optimal orbit configurations are met, repeated passes could be used for interferometric synthetic aperture radar (InSAR) processing in order to obtain high resolution topography. After two years of operation, Titan global topography could be available at $\mathrm{km}$ horizontal scale and meters scale vertical resolution, allowing much better accuracy than the one available today from Cassini [35].

In addition, synthetic aperture algorithms that were applied to the altimetry data could provide remarkable enhancement in spatial resolution when compared to the Cassini capabilities [36]. Further applications could include the investigation of any ephemeral event on specific areas of Titan, as rarely observed by Cassini $[37,38]$, the estimation of the liquid level of seas and lakes, characterization of rivers, sea and lake roughness, rain detection, atmosphere/clouds absorption, and dielectric properties estimation of solid and liquid. Finally, the system can be used to estimates the tides for the investigation of Titan's internal ocean by using repeated passes observations in altimetry mode acquired over the same location at different epochs. The selected radar frequencies and a suitable system design allow for this radar multimode instrument to operate alternatively as an altimeter, SAR, sounder, and/or radiometer by means of a programmable and adaptive on-orbit reconfiguration.

\section{Materials and Methods}

\subsection{Bathymetric Measurements of Titan's Seas}

The possible presence of a hydrocarbon global ocean on Titan, its depth, and composition, have been investigated prior to the Cassini arrival trough atmospheric-surface modelling [39-42] and ground based radar observation [43]. However, Cassini revealed that a global ocean of liquid hydrocarbons is not present, but large liquid filled basins are found to be mostly distributed at the northern hemisphere in form of seas and lakes. Differently, the southern hemisphere only shows few small liquid filled basins, in addition to the largest southern lake Ontario and a large number of basins that have been interpreted as paleoseas [44]. The dichotomy of the northern and southern hemisphere lakes distribution has been attributed to a long scale climate variation that is induced by the orbital configuration of Titan respect to Saturn [45].

Since the Cassini arrival, the depth and composition of Titan's seas and lakes have been an object of interest for several studies [46-49], while the first opportunity to perform a direct measurements of Titan's seas was only possible during fly-by T91 on May 2013, across the second largest sea, 
Ligeia Mare [25]. This represented the first direct measurement of an extraterrestrial bathymetric profile. The experiment that was conducted from $1500 \mathrm{~km}$ of altitude allowed for the radar on board Cassini, to directly probe the sea down to a maximum depth of $170 \mathrm{~m}$. Data that were acquired from this observation were used to create a topographic profile of the seafloor of Ligeia Mare and to constrain the liquid composition from signal attenuation [25,50]. Assuming a ternary mixture of methane-ethane-nitrogen composition, while using the laboratory measurements of [51] and applying the Lorentz-Lorenz formulation with nitrogen mixing ratios, as determined by [52], the measured loss tangent $\left(4 \pm 1 \times 10^{-5}\right)$ was converted into a mixture of approximately $71 \% \mathrm{CH}_{4}, 12 \% \mathrm{C}_{2} \mathrm{H}_{6}, 17 \%$ $\mathrm{N}_{2}$, which indicated that Ligeia was methane dominated at the time of observation. Moreover, by combining the information relative to the areal extension that was obtained from SAR images and assuming an average value of depth of $70 \mathrm{~m}$, the authors were able to extrapolate the total liquid volume of the basin, which resulted in $\sim 10^{4} \mathrm{~km}^{3}$ [25].

By means of the waveform fitting approach that was able to reproduce the saturation effects at the receiver [50], Mastrogiuseppe and colleagues re-analyzed saturated altimetric data that were acquired during fly-by T49 on 21 December 2008, to extract information regarding the depth and composition of southern Ontario Lacus [53]. An optimized signal processing, which adopted super resolution techniques [54,55], revealed the presence of lakebed signal reflections at $\sim 50 \mathrm{~m}$ of maximum depth, which was consistent with the indirect measurements of bathymetry as extrapolated from the shorelines slope measured from altimetry [46]. Assuming a similar ternary composition, the best fit loss tangent at Ontario Lacus $\left(6 \pm 3 \times 10^{-5}\right)$ was found to be consistent with $\sim 47 \% \mathrm{CH}_{4}, \sim 40 \%$ $\mathrm{C}_{2} \mathrm{H}_{6}$, and $\sim 13 \% \mathrm{~N}_{2}$. Similarly to Ligeia, Ontario appeared methane dominated, but the measured best fit loss tangent could indicate an increased abundance of higher order hydrocarbons, as observed from spectral VIMS analysis [56]. A detailed description of Ontario lacus and its geomorphology is described in $[57,58]$.

Following the T91 observation of Ligeia Mare, other experiments, which aimed at investigating Titan's seas and lakes in sounding mode, have been planned and executed. Specifically, during the fly-bys T104 on August 2014, T108 on January 2015 and T126 on April 2017, the Cassini RADAR observed the largest sea Kraken Mare, Punga Mare and the northern Lake District, respectively. While the seafloor was not detected at Kraken, which suggested that the sea was either too deep or too absorptive, a clear detection of the subsurface of Punga Mare was observed with a maximum depth of $120 \mathrm{~m}$. Similarly, during fly-by T126 the RADAR was able to probe Winnipeg Lacus down to $100 \mathrm{~m}$ of depth from an altitude of $1200 \mathrm{~km}$ [27]. The loss tangent analysis of these two observations indicates that the northern lakes and Punga Mare were similar in composition to Ligeia Mare during the time of observation. Table 1 reports the composition and bathymetry of the observed seas and lakes.

Table 1. Depths and composition of Cassini altimetric observation of Titan's seas and lakes.

\begin{tabular}{|c|c|c|c|c|c|c|}
\hline Sea/Lake & $\begin{array}{l}\text { Estimated } \\
\text { Depths }\end{array}$ & Tan Delta & Latitude & $\begin{array}{l}\text { Composition }{ }^{1} \\
\mathrm{CH}_{4} / \mathrm{C}_{2} \mathrm{H}_{6} / \mathrm{N}_{2}\end{array}$ & $\begin{array}{c}\text { Epoch of } \\
\text { Observation }\end{array}$ & Fly-By \\
\hline Ligeia Mare & 20-170 m & $4 \pm 1 \times 10^{-5}$ & $77^{\circ}-82^{\circ} \mathrm{N}$ & $71 / 12 / 17 \%$ & May 2013 & T91 \\
\hline Punga Mare & $20-120 \mathrm{~m}$ & $3 \pm 1 \times 10^{-5}$ & $83^{\circ}-84^{\circ} \mathrm{N}$ & $80 / 20 / 0 \%$ & January 2015 & T108 \\
\hline Baffin Sinus & $20-60 \mathrm{~m}$ & $3 \pm 1 \times 10^{-5}$ & $80^{\circ}-81^{\circ} \mathrm{N}$ & $80 / 20 / 0 \%$ & January 2015 & T108 \\
\hline Winnipeg & $20-100 \mathrm{~m}$ & $4 \pm 1 \times 10^{-5}$ & $78^{\circ} \mathrm{N}$ & $69 / 15 / 16 \%$ & April 2017 & T126 \\
\hline Ontario & $20-60 \mathrm{~m}$ & $6 \pm 3 \times 10^{-5}$ & $72^{\circ} \mathrm{S}$ & $47 / 40 / 13 \%$ & December 2008 & T49 \\
\hline Kraken Mare & Not Detected & - & $60^{\circ}-80^{\circ} \mathrm{N}$ & - & August 2014 & T104 \\
\hline
\end{tabular}

In Figure 1, we report a SAR mosaic of the northern polar region and the T91, T104, T108 altimetric tracks over the seas. The bottom part of the figure shows the relative radargram and bathymetric products that were obtained after processing. Figure 2 shows the SAR images of Ontario and Winnipeg Lacus and a waveform that was selected over the deepest portion of the track. 


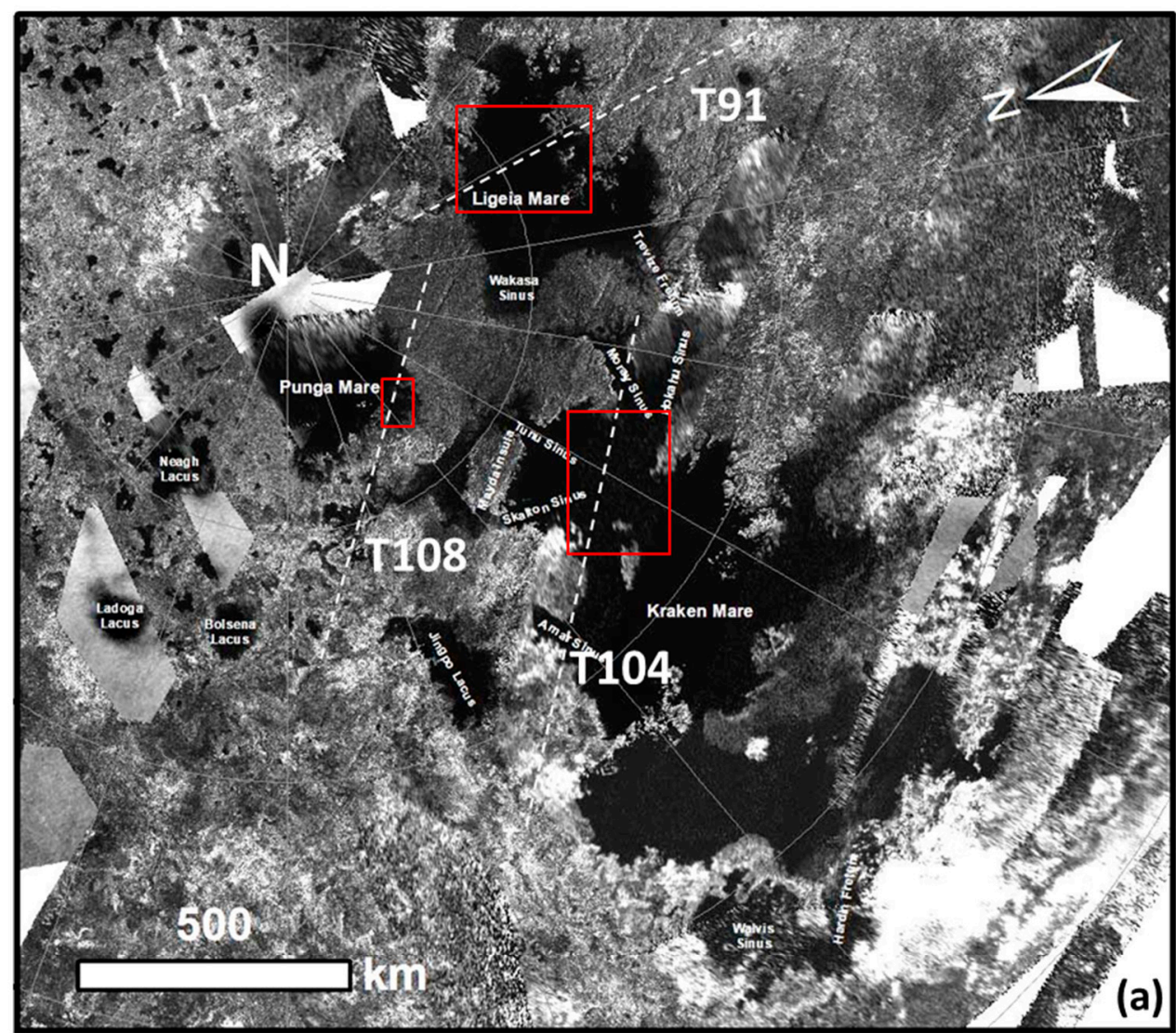

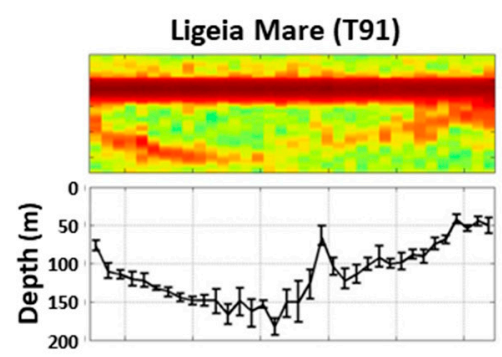

(b)

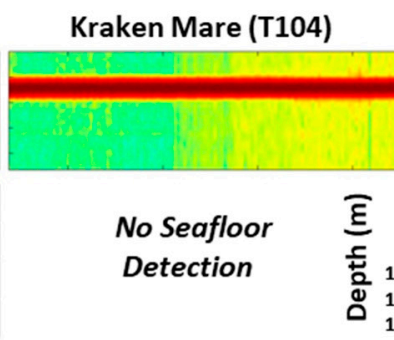

(c)
Punga Mare (T108)
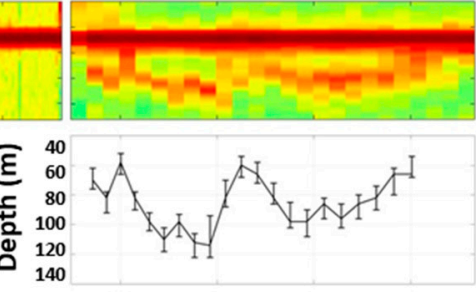

(d)

Figure 1. (a) Synthetic Aperture Radar (SAR) image mosaic of Titan's northern polar terrain and altimetric tracks acquired during fly-bys T91, T104, and T108 over Ligeia Mare, Kraken Mare, and Punga Mare, respectively. (b) Radargram obtained from T91 and relative bathymetry of Ligeia. (c) Radargram of Kraken Mare (T104) where no seafloor was detected. (d) Radargram of Punga Mare (T108) and relative bathymetry.

\subsection{Proposed System: Dual-Frequency Ka/X Bands Multimode Radar Orbiter}

Cassini provided important information regarding Titan's seas with only limited number of tracks. Radar investigation from an orbiter and in-situ measurements are envisaged in order to determine a detailed variability of sea composition, as well as the depth and composition of Titan's largest sea (Kraken Mare) [59,60]. Herein, we propose a dual-frequency radar system operating at X $(7.5 \mathrm{GHz})$ and $\mathrm{Ka}(32 \mathrm{GHz})$ bands from a $1500 \mathrm{~km}$ circular orbit. A $50 \mathrm{MHz}$ bandwidth system capable to provide $3 \mathrm{~m}$ of vertical resolution on free space has been selected in order to achieve sufficient accuracy for bathymetric measurements, Titan's imaging, and tides investigation. Data volume reduction will be accomplished through dedicate on board processing that will be applied to the specific radar mode. 

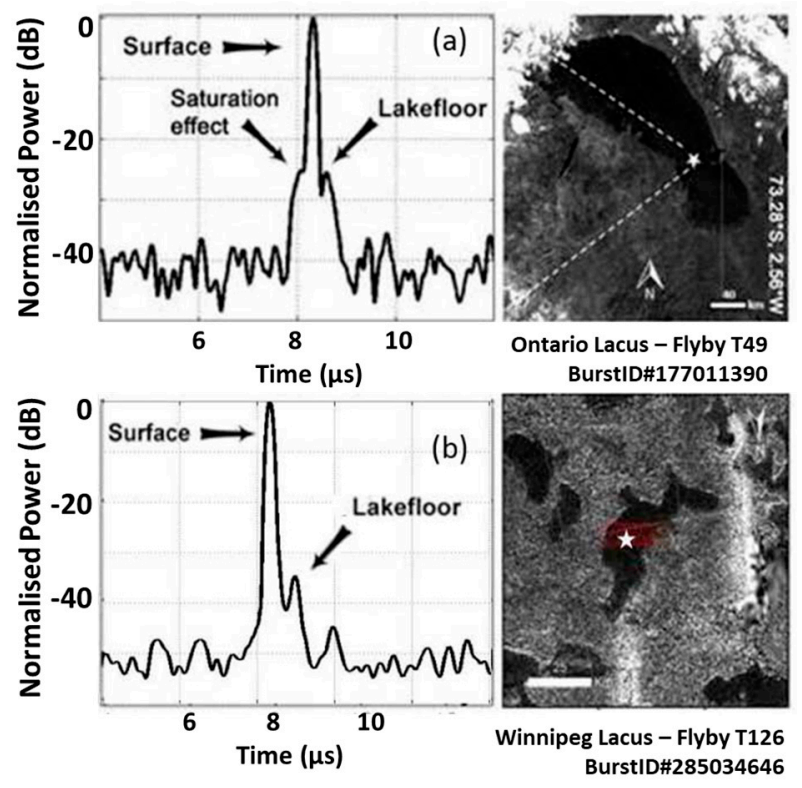

Figure 2. (a) Radar waveform acquired over Ontario Lacus during fly T49 and relative location over SAR image (b) Radar waveform acquired during fly-by T126 and relative SAR image of Winnipeg Lacus.

The onboard processing should be designed according to the various operative mode of the radar system. The Ka band has been designed for shallow bathymetry investigation and topographic measurements taking advantage of the higher signal to noise ratio (SNR) and the reduced footprint.

While the deepest part of the hydrocarbons seas could be difficult to probe at this frequency due to the high absorption, this band could provide high resolution bathymetry close to the shorelines or the composition and depth of shallow lakes.

We report the SNR calculated according to the radar equation and while taking a pulse limited geometry into account:

$$
S N R=\frac{P_{t} \cdot G_{a n t}^{2} \cdot \lambda^{2} \cdot \sigma \cdot B \cdot T}{(4 \pi)^{3} \cdot H^{4} \cdot K \cdot T_{e q} \cdot B} \sqrt{N}
$$

where all of the variables are reported in Table 2.

The radar cross section $\sigma$ can be evaluated according to the scenario which is expected to be observed. When considering an illuminated surface of area $A_{\text {surf }}$, reflectivity $\Gamma$ and a roughness with an rms slope equal to $m$, according to the Geometric Optics (GO) formulation, the radar cross section can be expressed as:

$$
\sigma=\sigma^{0} \cdot A_{\text {surf }}=\frac{\Gamma}{2 \cdot m^{2}} \cdot A_{\text {surf }}
$$

When considering the pulse-limited geometry, the illuminated area can be calculated as:

$$
A_{\text {surf }}=2 \cdot \pi \cdot H \cdot \delta_{r}
$$

where $\delta_{r}$ is the range resolution, which is related to the radar bandwidth by the following:

$$
\delta \mathrm{r}=0.88 \cdot \frac{\mathrm{C}}{2 \mathrm{~B}}
$$


Table 2. Radar Parameters for the proposed system.

\begin{tabular}{cccc}
\hline Symbol & Quantity & Unit & Value \\
\hline$P_{\mathrm{t}}$ & Tx Power & {$[\mathrm{W}]$} & 40 \\
$\mathrm{~L}$ & Antenna size & {$[\mathrm{m}]$} & 4 \\
$\mathrm{G}_{\mathrm{ant}}$ & Antenna Gain & {$[\mathrm{dB}]$} & $54\left(\mathrm{~K}_{\mathrm{a}}\right)$ \\
$\mathrm{T}$ & Tx Chirp Length & {$[\mu \mathrm{s}]$} & $42(\mathrm{X})$ \\
$\mathrm{H}$ & Altitude & {$[\mathrm{km}]$} & 150 \\
$\lambda$ & Wavelength & {$[\mathrm{m}]$} & 1500 \\
$\mathrm{~N}$ & Pulses \# & & $0.009\left(\mathrm{~K}_{\mathrm{a}}\right.$ band $)$ \\
$\mathrm{B}$ & Bandwidth & {$[\mathrm{MHz}]$} & $0.04(\mathrm{X}$ band $)$ \\
$\mathrm{T}_{\mathrm{eq}}$ & Eq. Temp. Rx & {$[\mathrm{K}]$} & 45 \\
$\mathrm{~K}$ & Boltzmann constant & {$[\mathrm{J} / \mathrm{K}]$} & 50 \\
$\delta_{\mathrm{r}}$ & Vertical res. & {$[\mathrm{m}]$} & 1000 \\
$\mathrm{R}_{\mathrm{az}}$ & Horizontal res. & {$[\mathrm{m}]$} & $1.38 \times 10^{-23}$ \\
$\mathrm{~V}_{\mathrm{t}}$ & Tangential Velocity & {$[\mathrm{km} / \mathrm{s}]$} & 3 \\
\hline
\end{tabular}

In Figure 3, a plot of the SNR at Ka and X band is shown, which is calculated for different values of the rms slope and $\Gamma=-11 d B$. In Table 2, we report the radar parameters and spatial resolution for the proposed system.

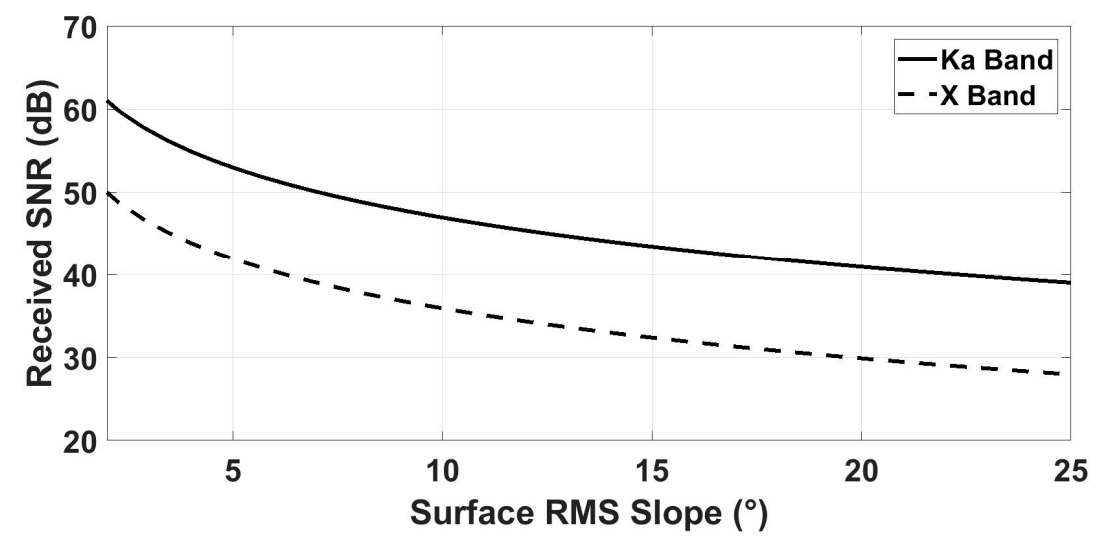

Figure 3. Calculated signal to noise ratio (SNR) for different values of rms slope.

\subsection{High-Resolution SAR and Interferometry Mode}

Here, we discuss the design of the main parameters for the proposed radar system when operating in off-nadir configuration as a SAR for high resolution mapping of Titan, and as an interferometer while using repeated passes [61,62] in order to obtain three-dimensional (3D) topography of the moon.

In Table 3, we report the main requirements for the proposed system.

Table 3. SAR system main requirements.

\begin{tabular}{ccc}
\hline Requirements & Unit & Value \\
\hline Ground Resolution & {$[\mathrm{m}]$} & $\leq 20$ \\
Height Measurements Accuracy & {$[\mathrm{m}]$} & $<5$ \\
Height Resolution & {$[\mathrm{m}]$} & $<50$ \\
Radiometric Resolution & {$[\mathrm{dB}]$} & $<1.2$ \\
Noise Equivalent & {$[\mathrm{dB}]$} & $<-15$ \\
\hline
\end{tabular}

The system can operate in strip map mode, allowing for collecting images over specific areas of the moon with a pixel resolution better than $20 \mathrm{~m}$ and a radiometric resolution better than $1.2 \mathrm{~dB}$, 
depending on the geometry of the observation. The horizontal resolution can be easily achieved via a matched filter applied to each received waveform and a multi-look can be performed in the azimuth direction, as well as in range when the off-nadir angle allows for sufficient ground resolution. The azimuthal resolution will be obtained while using a SAR processing applied to the received echoes. The pulse repetition frequency (PRF) of the system must be properly selected in order to correctly sample the Doppler bandwidth and avoid overlapping of the received echoes with transmitted waveforms. The off-nadir angle will vary according to the target of interest, however we will consider a values between 10-30 degree for the present analysis.

According to (5), the maximum resolution achievable in cross track direction ranges from 6 to $17 \mathrm{~m}$ for off-nadir angles of $30^{\circ}$ and $10^{\circ}$, respectively:

$$
R_{\text {range }}=\frac{c}{2 \cdot B \cdot \sin (\alpha)}
$$

The limit for the azimuth resolution is driven by the antenna system according to the physical dimension of the antenna in along track $(L)$ :

$$
R_{a z}=\frac{L}{2}
$$

which for the proposed system reach a value of $R_{a z}=2 \mathrm{~m}$.

Based on the ground resolution requirements, a multi-look average by a factor of 10 can be always performed, therefore according to (7), the radiometric resolution requirements in Table 3 can be always achieved:

$$
R_{r}=10 \cdot \log 10\left[1+\left(1+\frac{1}{S N R^{2}}\right) \cdot \frac{1}{\sqrt{N L}}\right]
$$

The main parameter that remains to be set is the SAR PRF. A lower bound can be set to $0.8 \mathrm{KHz}$, as obtained from the antenna physical dimension and tangential velocity $V_{t}$ from:

$$
P R F_{\min }>\frac{2 V_{t}}{L}
$$

It is worth noting that this limit does not depend on the operative frequency.

The upper bound can be calculated from (9) in order to avoid the overlapping of transmitted and received waveforms.

$$
P R F_{\max }<\frac{c \cdot L \cdot \cos (\alpha)}{2 \cdot \lambda \cdot H \cdot \operatorname{tg}(\alpha)}
$$

We found values of $66 \mathrm{KHz}$ and $15 \mathrm{KHz}$ for the $\mathrm{Ka}$ and $\mathrm{X}$ bands, respectively.

The calculated PRF only indicates the lower and upper limits and it should be adjusted for accounting of the ambiguity of the returned echoes. For our proposal, we found as good choice a PRF of $5 \mathrm{KHz}$, which is able to satisfy the PRF requirements at both frequencies.

\subsection{Interferometric System}

The proposed system can also operate as an interferometer by means of repeated passes when the favorable orbital conditions are met. The height resolution can be defined as the value of the height, which generates a phase rotation of the signal equal to $2 \pi$ and it is defined by:

$$
\Delta q \approx \frac{\lambda \cdot H \cdot \operatorname{tg}(\alpha)}{2 B_{s} \cdot \cos (\alpha)}
$$

where $B s$ is the spatial baseline (i.e., distance of repeated tracks).

Therefore, the baseline must be greater than $50 \mathrm{~m}$ in Ka and $220 \mathrm{~m}$ in X band in order to obtain an height resolution better than the requirements in Table 3; these requirements are followed by an 
upper limit value of the baseline, which is dictated by the decorrelation of the signal when a scenario is observed from different angles of view. Such an upper limit can be calculated using:

$$
\sigma_{\Delta \varphi}=\frac{1}{\sqrt{2 N_{L}}} \frac{\sqrt{\left(1+S N R^{-1}\right)^{2}-\rho^{2}}}{\rho}
$$

where $\rho$ is the modulus of the complex correlation coefficient, which only depends on the geometric parameters:

$$
\rho=1-\frac{2 r_{y} \cdot B_{s} \cdot \cos ^{3}(\alpha)}{\lambda \cdot H}
$$

and $r_{y}$ is the along track ground resolution.

Assuming no co-registration errors, normalized errors can be calculated while using the following:

$$
e_{n}=\sqrt{N_{L}} \cdot \sigma_{q} / r_{y}
$$

where $\sigma_{q}$ is the error on the estimated heights and it can be obtained combining the height resolution in (10) and the phase error as reported in (11).

Optimum horizontal baseline can be calculated by imposing a limit on the error. In Figure 4, we plot the error as function of the horizontal baseline for a system having $10 \mathrm{~dB}$ of SNR and $N_{L}=10$. We found an optimal Bs ranging from 220 to $1200 \mathrm{~m}$ and 50 to $260 \mathrm{~m}$ for the $X$ and Ka band, respectively (see Figure 4), for example, while considering errors $e_{n}<0.2$.

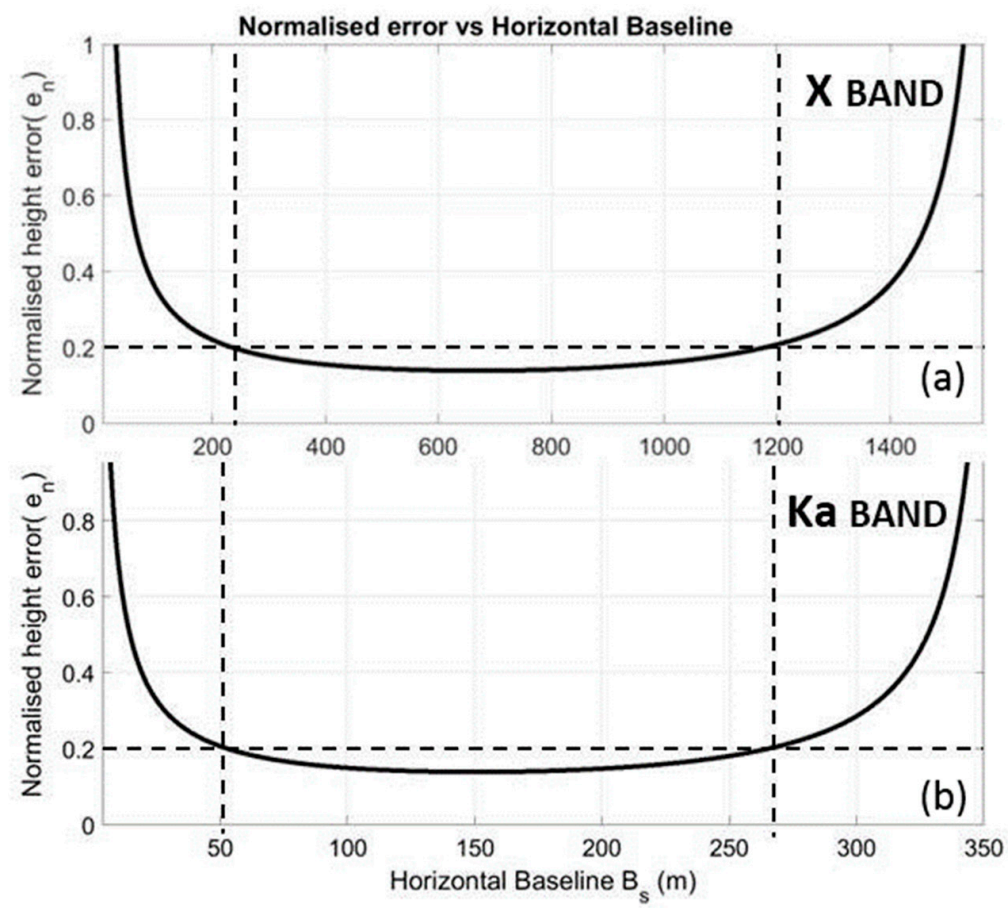

Figure 4. Optimal baseline evaluation as function of the normalized error for $\mathrm{X}$ band (a) and $\mathrm{Ka}$ band (b).

\subsection{Tides Measurements and Global Topography}

Saturn's largest moon, Titan, hosts a subsurface liquid water ocean that is likely composed of water and ammonia [63-66]. Titan also hosts extensive organic deposits across its surface and a hydrological cycle of hydrocarbons exchanged between the surface and atmosphere, making the environment of this moon particularly attractive in terms of extraterrestrial habitability $[67,68]$. Titan's ice shell is expected to be $\sim 100 \mathrm{~km}$ in thickness $[69,70]$, therefore an investigation of the ocean performed while using 
typical radar sounding systems, such as MARSIS and SHARAD [71,72], becomes challenging due to the limited penetration capability of such instruments. Alternatively, a radar altimeter can indirectly characterize subsurface properties, such as density of the internal ocean and ice shell thickness, through geophysical measurements of the tidal potential Love number $k 2$ and $h 2$. Such estimation can be performed via tides and topography measurements, along with the support of gravitational data through radio science instruments [73].

Tides models on Titan have been investigated for the solid surface [74] as well as for the polar hydrocarbons liquids [75-79]. A detailed description of the effects of tides on Titan's polar liquid hydrocarbons is reported in [80]. The maximum vertical solid surface displacement is estimated to range between $10 \mathrm{~m}$ and $30 \mathrm{~m}$ at the poles and equator, respectively, for a model that accounts for the presence of an ocean [81]. The tidal Love numbers (h2 and k2) should be estimated with an accuracy on the order of $1 \%$ and $0.1 \%$ in order to investigate the characteristics of the ocean and the thickness of the ice shell, respectively, which requires centimeter-scale knowledge of the tidal amplitudes.

Altimetry satellites, such as POSEIDON [82], have provided centimeter scale accuracy of terrestrial surface height measurements, which allows for a global ocean characterization and topography at very high accuracy [83], obtained while using a radar system with hundreds $\mathrm{MHz}$ bandwidth, and knowledge of the spacecraft ephemerids in order of ten centimeters. Radar altimetry has greatly improved our knowledge of ocean tides on Earth [84]. Instruments, such as Jason1 and ERS, have observed the Earth more than 15 years, providing information regarding the global changes in both ocean circulation and sea level. A radar altimeter can measure tides using a network of single-point crossovers or though repeat adjacent ground tracks (see Figure 5) separated by less than the cross-track radar footprint [85]. Both of the methods provide differential measurements of the surface height (i.e., using the two-way travel time echo) acquired at the same location, but different true anomalies.

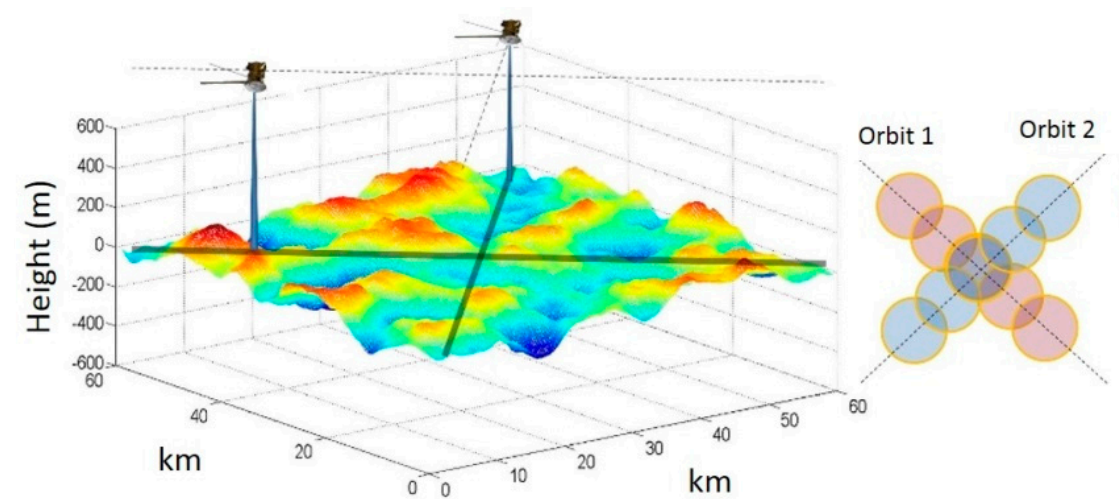

(a) (b)

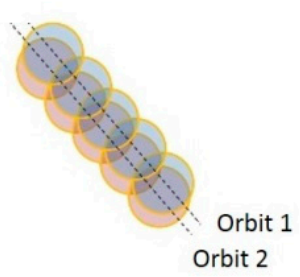

(c)

Figure 5. (a) Tides estimation via repeated ground track. (b) The crossover technique allows for having one differential range measurement for each pair of observation. (c) Repeated adjacent track configuration is less frequent, but it allows for multiple measurements for each pair.

The estimation of tidal amplitudes can be performed while using an inverse model and the Love number $\mathrm{h} 2$ can be estimated with an accuracy that will mainly depend on the number of crossovers, the altimeter range accuracy, and the spacecraft positioning errors. When a large percentage of footprint superimposition is available, differential range measurements can be performed with an accuracy that is better than the radar resolution. While the crossover technique only allows few measurements for each pair of orbits, repeat ground tracks allows for multiple measurements while using a single pair of observations (see Figure 5). However, repeated ground tracks require the orbits to be close enough to have substantial overlap between footprints, and such a configuration is rarely met when compared to the crossovers that naturally occur in typical orbital geometries. The adjacent ground track technique (see Figure 5c) is particularly attractive, as long repeated ground tracks permit a large number of overlapped footprints to be collected and the potential Love number h2 can be estimated with high 
accuracy after acquiring only a few pairs of repeat passes. Observations should be planned in order to observe tides at different phases, for example, when the true anomaly of Titan is at 0 and 180 degree.

\section{Discussion and Results}

\subsection{Sounding Mode Operative Frequency Optimization}

The $\mathrm{X}$ band frequency has been designed to provide bathymetry and composition of the deepest portion of the seas, taking advantage of the improved penetration capabilities at a lower frequency. The trade-off for operative frequency selection has been investigated, as shown in Figure 6. The detection capabilities of a radar system operating from $1500 \mathrm{~km}$ circular orbit and using a $4 \mathrm{~m}$ dish antenna are shown as function of operative frequency for different values of liquid loss tangent $\left(3 \times 10^{-5}\right.$ and $\left.1 \times 10^{-4}\right)$ and depths $(50,100,200$, and $400 \mathrm{~m})$.
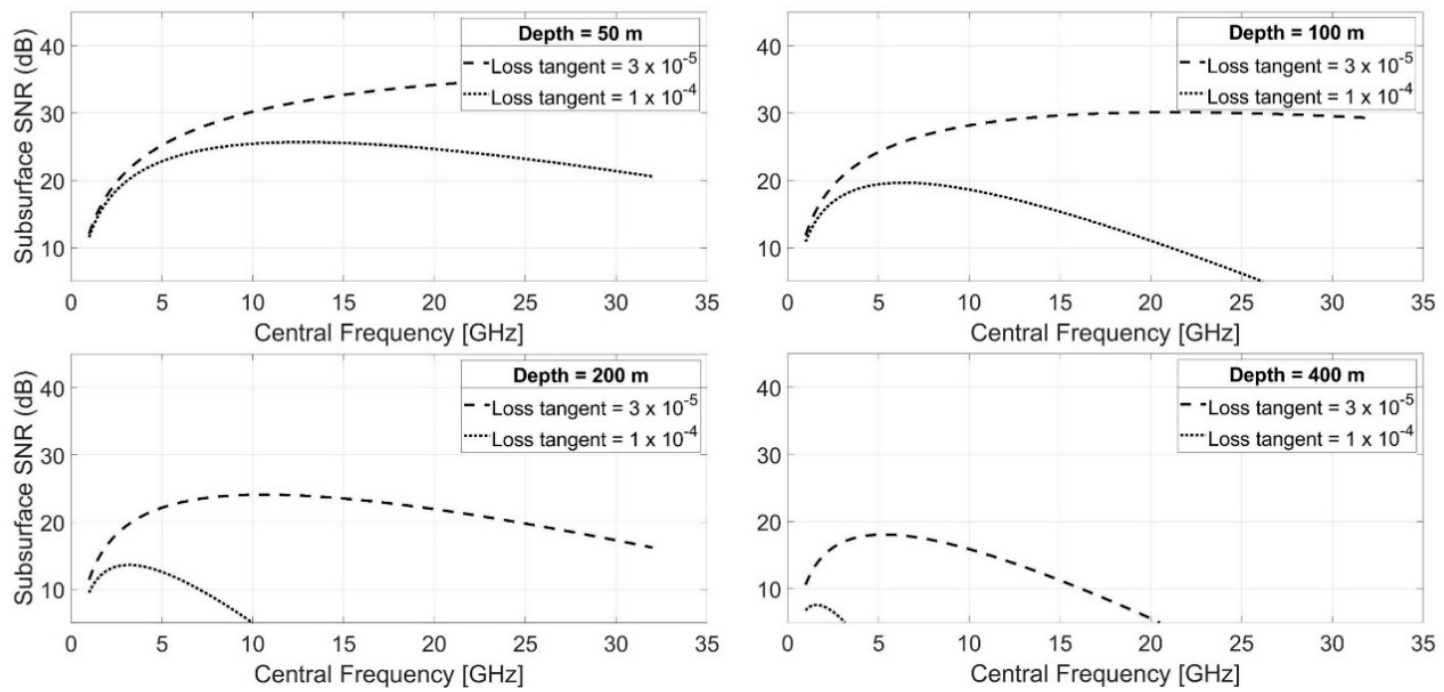

Figure 6. Detection capabilities of the proposed system for different values of liquid loss tangent $\left(3 \times 10^{-5}\right.$ and $\left.1 \times 10^{-4}\right)$ and depths $(50,100,200$, and $400 \mathrm{~m})$ as function of operative frequency. Note that for shallow depths and low values of loss tangent ((a) panel), Ka performs better than the other bands thanks to the higher SNR achieved from the increased antenna gain. For greater depths and larger values of loss tangent, the SNR at higher frequencies decreases due to the column liquid attenuation and lower frequencies are preferred.

The curves in Figure 6 are obtained by combining SNR, as calculated in Figure 3, and subsurface power return $\mathrm{P}_{\mathrm{sS}}$ according to the following formulation:

$$
\left.\frac{P_{s}}{P_{S S}}\right|_{d B}=\left.\Gamma_{s}\right|_{d B}-\left.\left(1-\Gamma_{S S}\right)^{2}\right|_{d B}-\left.\Gamma_{s s}\right|_{d B}+\left.K\right|_{d B}+\left.\frac{f_{s}}{f_{S S}}\right|_{d B}
$$

With

$$
\left.K\right|_{d B}=27 * \tan \delta * f * \Delta \tau
$$

where tan $\delta$ is the loss tangent of the media, $f$ is the central frequency expressed in $\mathrm{MHz}$, and $\Delta \tau$ is the two-way travel time expressed in microseconds and related to the depth by the follow:

$$
\Delta \tau=2 d * n / c
$$

where $n$ is the index refraction of the media and $c$ is the speed of light.

Terms $\left.\Gamma_{s}\right|_{d B}$ and $\left.\Gamma_{s s}\right|_{d B}$ are the surface and subsurface reflectivity (in decibel) that are related to dielectric property $\varepsilon_{r 1}$ and $\varepsilon_{r 2}$ by the following:

$$
\Gamma_{s}=\left|\frac{1-\sqrt{\varepsilon_{r 1}}}{1+\sqrt{\varepsilon_{r 1}}}\right| \quad \Gamma_{s s}=\left|\frac{\sqrt{\varepsilon_{r 1}}-\sqrt{\varepsilon_{r 2}}}{\sqrt{\varepsilon_{r 1}}+\sqrt{\varepsilon_{r 2}}}\right|
$$


We can note that, for shallow depths and low loss tangent, the Ka system provides better performance thanks to the higher signal to noise ratio that was achieved as the frequency is increased (see Figure 3 panel (a)).

The two operative frequencies could be interlaced or selected according to the scientific target. Specifically, the quasi-simultaneous use of the two frequencies can be used to improve the estimation of liquid loss tangent from radar attenuation. Similar techniques that aim to estimate radar attenuation at different frequencies and for increasing depths have been also applied to Martian sounders data [86-88] as well as Cassini data [2,26,27]. The $X$ band frequency could provide the detection of the sea floor of Kraken Mare, allowing for mapping the overall seabed topography of Titan's seas. If Kraken has a similar loss tangent to Ligeia, the $X$ band frequency would penetrate to depths of up to 800-900 m. Moreover, a three dimensional bathymetric map could be generated while using repeated passes observations, and the liquid attenuation could be estimated with a high accuracy at both frequencies and at different locations (both different lakes/seas as well as different locations within each lake/sea), allowing for the investigation of spatial and temporal variation of the liquid composition and depth. When combined with any radiometric measurements, the system could provide additional information regarding the dielectric properties of Titan's liquid, as well as sea floor and the exposed solid surface $[89,90]$. A multilayer simulator [91] has been used to generate simulations for the proposed system in order to present how radar products would appear when observing Titan's seas. Specifically, in Figure 7, a comparison between the radagrams of Ligeia Mare is shown that would be obtained by adopting the system parameters of the Cassini radar and those of the proposed architecture. Please note that loss tangent values that were adopted to generate Figures 6 and 7 are only indicative and reliable relationship of loss tangent as a function of frequency for any specific materials deserves further investigation by direct laboratory experiment.
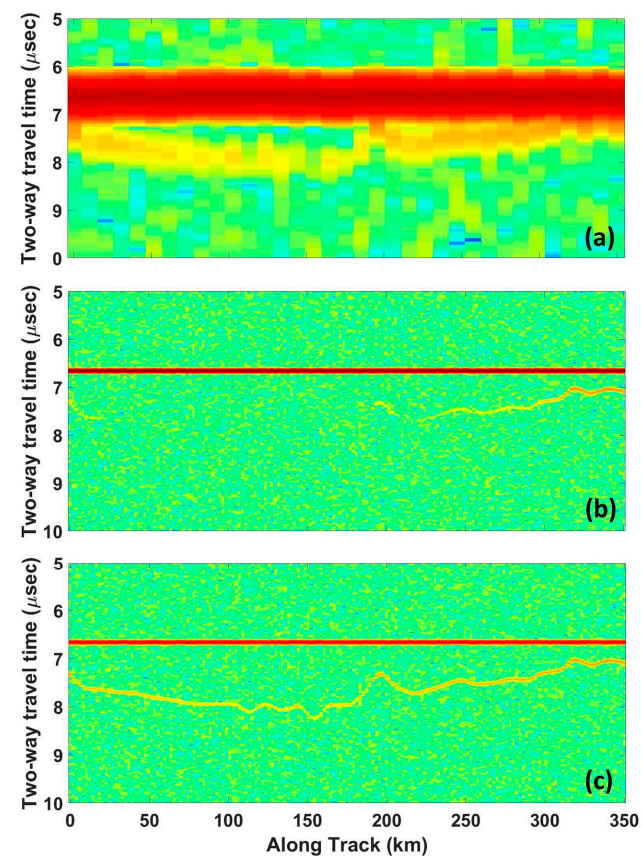

Figure 7. (a) Simulation Ligeia Mare T91 observation. Loss tangent of the liquid has been set at $4 * 10^{-5}$, $\varepsilon_{r 1}$ and $\varepsilon_{r 2}$ to 1.7 and 3.1, respectively. Subsurface roughness term $\mathrm{f}_{\mathrm{sS}}$ has been set to match observed radar amplitude. $(\mathbf{b}, \mathbf{c}) \mathrm{Ka}$ and $\mathrm{X}$ bands, respectively, simulations of T91 observation while using the proposed radar system.

Note that these simulations are not intended to capture the full characteristics of the radar echoes waveform (i.e., roughness and pulse- limited effects), but only to qualitatively show the effects of attenuation as frequency increases and the radar parameters are kept constant. 


\subsection{Tides Estimation Using Repeated Ground Tracks: Simulation and Results}

Herein, we investigate tides amplitude estimation accuracy from radar data simulation. We simulate the radar response of the proposed system using a fractal surface and a facets based simulator [2]. Surface characteristics are chosen by taking into account the available information regarding Titan's topography and the backscattering at each facets is represented via Hagfors scattering. Each overlap of ground tracks is simulated over a $4000 \times 100 \mathrm{~km}$ surface, which represent the observed topography that was acquired from the pole to equator at true anomalies of 180 and 0 degrees. Tidal effects are included while using the model that was reported by [81], in which it allowed the vertical surface displacement to vary as a function of the latitude for a fixed longitude of 0 degrees. Figure $8 \mathrm{a}$ reports the result of the surface displacement due to tides. A PRF of $5 \mathrm{KHz}$, a $32 \mathrm{GHz} \mathrm{Ka}$ frequency, and a bandwidth of $50 \mathrm{MHz}$ have been used to simulate 1330 bursts that were acquired along $4000 \mathrm{~km}$ surface. The same realization of the fractal surface is used twice, including tidal surface variation while assuming an h2 equal to 1.45 and different values of horizontal baselines for the two adjacent ground tracks. In Figure 8b, we show the result of the application of an OCOG tracking algorithm [92] applied to the two products, in which blue and red indicate the first and second acquisition at opposite true anomalies and horizontal baseline of $2 \mathrm{~km}$. It is possible to note that the effects of tides are already notable in the retrieved altimetry.
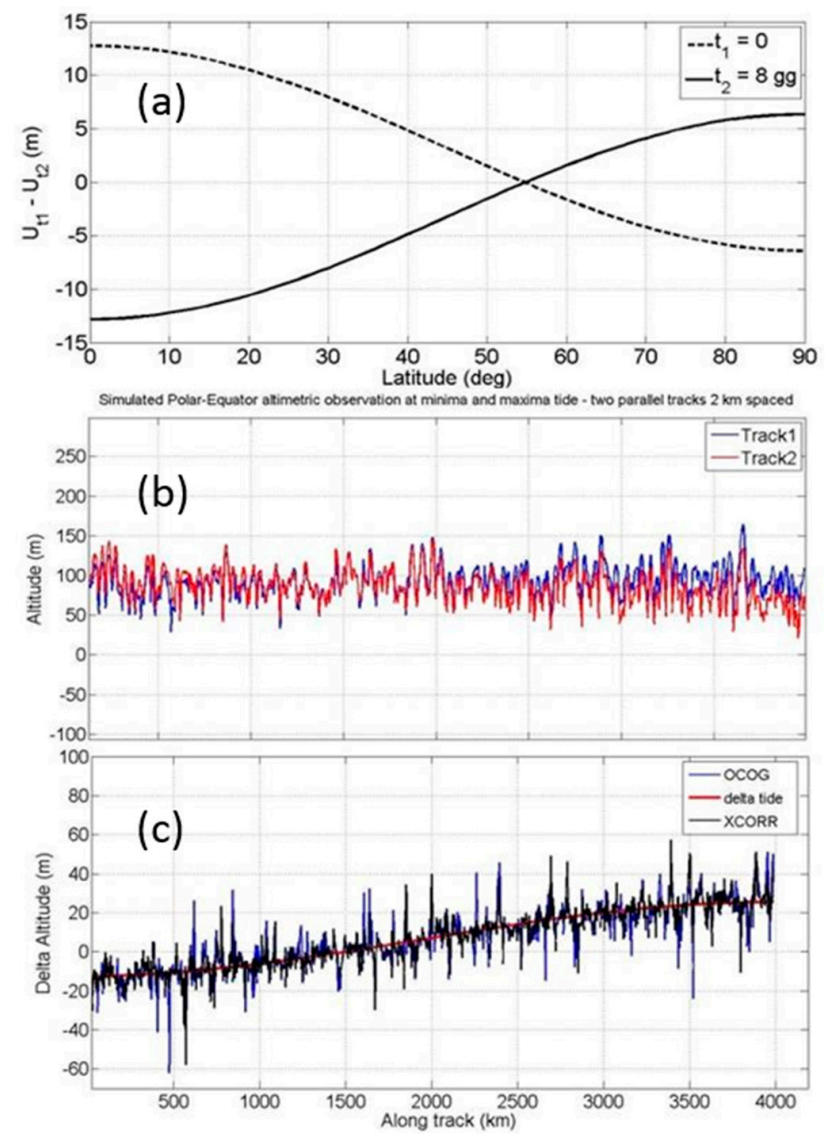

Figure 8. (a) Tidal surface displacement at opposite true anomalies 0 and 180 degree, and for latitudes varying from the Pole to the Equator at 0 degree of longitude. (b) Over plot of the result of OCOG algorithm applied to the first (blue) and second (red) repeated ground tracks. (c) Detected signal from repeated passes, $2 \mathrm{~km}$ adjacent ground tracks. In blue is the results of the OCOG algorithm, and in black is the cross correlation method. The red curve indicates the actual difference of the model.

We use two different methods for the estimating the Tidal Love number $\mathrm{h} 2$ from synthetic data. While the first method uses the difference of the altimetry from the two passes while using the OCOG 
algorithm, the second method exploits the knowledge of the offset between the two altimetry profiles, which were obtained by using the cross-correlation technique applied to the individual pairs of echoes (i.e., echoes of the two ground tracks at minimum distance). Figure $8 \mathrm{c}$ shows the detected tidal signal that was obtained while using the proposed methods. From our results, the cross correlation technique results are more accurate than the OCOG method, especially when the horizontal baseline (i.e., distance between the repeated ground tracks) is moderate, for example, less than $1 \mathrm{~km}$ for the proposed system.

The tidal Love number $\mathrm{h} 2$ can be estimated while using a least square solution to solve the linear system that relates the observable tidal surface displacement to the Love number [82].

The results in Table 4 shows that estimation of $\mathrm{h} 2$ can be performed with an accuracy of $0.1-0.2 \%$ from a single pair of repeated ground tracks when the cross-track separation is close enough to keep the received signal correlated. Table 4 shows the same scenario that we evaluated, except for varying the cross-track spacing between the two ground tracks and the RMS height of the simulated fractal surface.

Table 4. Accuracy of the estimate Love number h2.

\begin{tabular}{cccccccc}
\hline $\begin{array}{c}\text { Bh } \\
{[\mathbf{k m}]}\end{array}$ & $\begin{array}{c}\text { sigmaH } \\
{[\mathbf{m}]}\end{array}$ & $\begin{array}{c}\text { Mean } \\
\text { OCOG }\end{array}$ & $\begin{array}{c}\text { Err } \\
\text { OCOG }\end{array}$ & $\begin{array}{c}\text { OCOG } \\
\mathbf{( \% )}\end{array}$ & $\begin{array}{c}\text { Mean } \\
\text { xcor }\end{array}$ & $\begin{array}{c}\text { Err } \\
\text { xcor }\end{array}$ & $\begin{array}{c}\text { XCOR }^{\mathbf{1}} \\
(\mathbf{\%})\end{array}$ \\
\hline 3 & 20 & 1.50 & 0.027 & 1.79 & 1.50 & 0.026 & 1.72 \\
3 & 30 & 1.41 & 0.040 & 2.86 & 1.42 & 0.04 & 2.83 \\
2 & 20 & 1.42 & 0.025 & 1.77 & 1.44 & 0.017 & 1.21 \\
1 & 20 & 1.45 & 0.012 & 0.84 & 1.45 & 0.005 & 0.32 \\
0.6 & 30 & 1.47 & 0.012 & 0.83 & 1.45 & 0.004 & 0.25 \\
0.3 & 30 & 1.44 & 0.008 & 0.57 & 1.45 & 0.002 & 0.13 \\
\hline
\end{tabular}

${ }^{1}$ xcor calculates shifts using cross-correlation of waveforms.

We can note that, for baselines smaller than $0.5 \mathrm{~km}$, the Love number can be estimated within $0.2 \%$ of accuracy while only using a single pair of repeated orbits. Using only a few observations that were dedicated to the repeated adjacent track mode, this modeling shows that $\mathrm{h} 2 \mathrm{can}$ be estimated to within the required accuracy that is necessary to characterize the density of the internal ocean $(\sim 0.1 \%)$. Similarly, when considering cross-overs, a distance that is smaller than $0.5 \mathrm{~km}$ and a number of them close to one-thousand is sufficient to allow for a very accurate estimate of Titan's Love number.

\section{Conclusions}

The Cassini mission, and in particular its RADAR instrument, have revealed the presence of several geological features and landscapes which have greatly improved our understanding of Titan's complex environment [93]. Here, we have described the design and the scientific motivation of a dual frequency radar system for the exploration of Titan seas and tides from a $1500 \mathrm{~km}$ circular orbit. The proposed system could provide new insights and help to answer the scientific questions that were raised during and after the Cassini mission [94]. The orbiter could provide information regarding the global composition and topography of the moon by combing data that were acquired from future in situ mission such as DragonFly, the robotic rotorcraft lander designed to explore Titan on 2034. The studies presented here have general validity and they could be used in the framework of terrestrial applications, as well as future missions. Specifically, tides are an object of interest for the exploration of the interior of the Galilean moons and the techniques presented here could be proposed for next coming missions, such as Europa Clipper and RIME [95]. Moreover, the bathymetry and composition studies reported here could benefit the interpretation of ground penetrating radars, which are becoming an attractive tool for the exploration of shallow terrestrial lakes and rivers [96].

Funding: This research was funded by NASA, grant number [80NM0018D004].

Acknowledgments: The author was originally supported by the Italian Space Agency. The author is grateful to Charles Elachi and Steve Wall for the fruitful discussions about the Cassini mission and the interpretation of RADAR data. The author would also thanks Marica Raguso, Valerio Poggiali and Alex Hayes, whose comments helped to improve the quality of this work. 
Conflicts of Interest: The authors declare no conflict of interest. The funders had no role in the design of the study; in the collection, analyses, or interpretation of data; in the writing of the manuscript, or in the decision to publish the results.

\section{References}

1. Elachi, C.; Allison, M.D.; Borgarelli, L.; Encrenaz, P.; Im, E.; Janssen, M.A.; Johnson, W.T.K.; Kirk, R.L.; Lorenz, R.D.; Lunine, J.I.; et al. Radar: The Cassini Titan Radar Mapper. Space Sci. Rev. 2004, 115, 71-110. [CrossRef]

2. Mastrogiuseppe, M.; Poggiali, V.; Seu, R.; Martufi, R.; Notarnicola, C. Titan dune heights retrieval by using Cassini Radar Altimeter. Icarus 2014, 230, 191-197. [CrossRef]

3. Le Gall, A.; Janssen, M.; Wye, L.; Hayes, A.; Radebaugh, J.; Savage, C.; Zebker, H.; Lorenz, R.; Lunine, J.; Kirk, R.; et al. Cassini SAR, radiometry, scatterometry and altimetry observations of Titan's dune fields. Icarus 2011, 213, 608-624. [CrossRef]

4. Rodriguez, S.; García, A.; Lucas, A.; Appéré, T.; Le Gall, A.; Reffet, E.; Le Corre, L.; Le Mouélic, S.; Cornet, T.; Du Pont, S.C.; et al. Global mapping and characterization of Titan's dune fields with Cassini: Correlation between RADAR and VIMS observations. Icarus 2014, 230, 168-179. [CrossRef]

5. Lorenz, R.D. The Sand Seas of Titan: Cassini RADAR Observations of Longitudinal Dunes. Science 2006, 312, 724-727. [CrossRef]

6. $\quad$ Radebaugh, J.; Lorenz, R.D.; Lunine, J.I.; Lunine, S.D.; Wall, G.; Boubin, E.; Reffet, R.L.; Kirk, R.M.; Lopes, E.R.; Stofan, L.; et al. Spencer, and Cassini Radar Team,: Dunes on Titan observed by Cassini Radar. Icarus 2008, 194, 690-703. [CrossRef]

7. Poggiali, V.; Mastrogiuseppe, M.; Callegari, M.; Martufi, R.; Seu, R.; Casarano, D.; Pasolli, L.; Notarnicola, C. Synergy of Cassini SAR and altimeter acquisitions for the retrieval of dune field characteristics on Titan. In Proceedings of the SPIE 8536, SAR Image Analysis, Modeling, and Techniques XII, Prague, Czech Republic, 21-22 September 2012; Volume 853608.

8. Callegari, M.; Casarano, D.; Mastrogiuseppe, M.; Poggiali, V.; Notarnicola, C. Dune Height Estimation on Titan Exploiting Pairs of Synthetic Aperture Radar Images With Different Observation Angles. IEEE J. Sel. Top. Appl. Earth Obs. Remote Sens. 2015, 8, 1295-1306. [CrossRef]

9. Le Gall, A.; Hayes, A.; Ewing, R.; Janssen, M.; Radebaugh, J.; Savage, C.; Encrenaz, P. Latitudinal and altitudinal controls of Titan's dune field morphometry. Icarus 2012, 217, 231-242. [CrossRef]

10. Bonnefoy, L.E.; Hayes, A.G.; Hayne, P.O.; Malaska, M.J.; Le Gall, A.; Solomonidou, A.; Lucas, A. Compositional and spatial variations in Titan dune and interdune regions from Cassini VIMS and RADAR. Icarus 2016, 270, 222-237. [CrossRef]

11. Radebaugh, J.; Lorenz, R.D.; Kirk, R.L.; Lunine, J.I.; Stofan, E.R.; Lopes, R.M.; Wall, S.D. Mountains on Titan observed by Cassini Radar. Icarus 2007, 192, 77-91. [CrossRef]

12. Mitri, G.; Bland, M.T.; Showman, A.P.; Radebaugh, J.; Stiles, B.; Lopes, R.M.C.; Lunine, J.I.; Pappalardo, R.T. Mountains on Titan: Modeling and observations. J. Geophys. Res. Space Phys. 2010, 115, 115. [CrossRef]

13. Barnes, J.W.; Radebaugh, J.; Brown, R.H.; Wall, S.; Soderblom, L.; Lunine, J.; Burr, D.; Sotin, C.; Le Mouélic, S.; Rodriguez, S.; et al. Near-infrared spectral mapping of Titan's mountains and channels. J. Geophys. Res. Space Phys. 2007, 112. [CrossRef]

14. Wood, C.A.; Lorenz, R.; Kirk, R.; Lopes, R.; Mitchell, K.; Stofan, E. Impact craters on Titan. Icarus 2010, 206, 334-344. [CrossRef]

15. Lopes, R.M.C.; Kirk, R.L.; Mitchell, K.L.; LeGall, A.; Barnes, J.W.; Hayes, A.; Kargel, J.; Wye, L.; Radebaugh, J.; Stofan, E.R.; et al. Cryovolcanism on Titan: New results from Cassini RADAR and VIMS. J. Geophys. Res. Planets 2013, 118, 416-435. [CrossRef]

16. Hayes, A.G.; Birch, S.P.D.; Dietrich, W.E.; Howard, A.D.; Kirk, R.L.; Poggiali, V.; Mastrogiuseppe, M.; Michaelides, R.J.; Corlies, P.M.; Moore, J.M.; et al. Topographic Constraints on the Evolution and Connectivity of Titan's Lacustrine Basins. Geophys. Res. Lett. 2017, 44, 745-753. [CrossRef]

17. Michaelides, R.; Hayes, A.; Mastrogiuseppe, M.; Zebker, H.; Farr, T.; Malaska, M.; Poggiali, V.; Mullen, J.; Farr, T.; Malaska, M. Constraining the physical properties of Titan's empty lake basins using nadir and off-nadir Cassini RADAR backscatter. Icarus 2016, 270, 57-66. [CrossRef] 
18. Birch, S.P.D.; Hayes, A.G.; Poggiali, V.; Hofgartner, J.D.; Lunine, J.I.; Malaska, M.J.; Wall, S.; Lopes, R.M.C.; White, O. Raised Rims Around Titan's Sharp-Edged Depressions. Geophys. Res. Lett. 2019, 46, 5846-5854. [CrossRef]

19. Solomonidou, A.; Le Gall, A.; Malaska, M.J.; Birch, S.P.D.; Lopes, R.M.C.; Coustenis, A.; Rodriguez, S.; Wall, S.D.; Michaelides, R.J.; Nasr, M.R.; et al. Spectral and emissivity analysis of the raised ramparts around Titan's northern lakes. Icarus 2019. [CrossRef]

20. Mitri, G.; Lunine, J.I.; Mastrogiuseppe, M.; Poggiali, V. Possoble exlpotion crater origin of small lake basins with raised rims on Titan. Nat. Geosci. 2019. [CrossRef]

21. Stofan, E.R.; Elachi, C.; Lunine, J.I.; Lorenz, R.D.; Stiles, B.; Mitchell, K.L.; Ostro, S.; Soderblom, L.; Wood, C.; Zebker, H.; et al. The lakes of Titan. Nature 2007, 445, 61-64. [CrossRef]

22. Lunine, J.I.; Atreya, S. The Methane Cycle on Titan. Nat. Geosci. 2008, 1, 159-162. [CrossRef]

23. Hayes, A.; Aharonson, O.; Callahan, P.; Elachi, C.; Gim, Y.; Kirk, R.; Lewis, K.; Lopes, R.; Lorenz, R.; Lunine, J.; et al. Hydrocarbon lakes on Titan: Distribution and interaction with a porous regolith. Geophys. Res. Lett. 2008, 35. [CrossRef]

24. Birch, S.P.D.; Hayes, A.G.; Dietrich, W.E.; Howard, A.D.; Bristow, C.S.; Malaska, M.J.; Moore, J.M.; Mastrogiuseppe, M.; Hofgartner, J.D.; Williams, D.A.; et al. Geomorphologic Mapping of Titan's polar terrains: Constraining Surface Processes and Landscape Evolution. Icarus 2017, 282, 214-236. [CrossRef]

25. Mastrogiuseppe, M.; Poggiali, V.; Hayes, A.; Lorenz, R.; Lunine, J.; Picardi, G.; Seu, R.; Flamini, E.; Mitri, G.; Notarnicola, C.; et al. The bathymetry of a Titan sea. Geophys. Res. Lett. 2014, 41, 1432-1437. [CrossRef]

26. Mastrogiuseppe, M.; Poggiali, V.; Hayes, A.G.; Lunine, J.I.; Seu, R.; Di Achille, G.; Lorenz, R.D. Cassini radar observation of Punga Mare and environs: Bathymetry and composition. Earth Planet. Sci. Lett. 2018, 496, 89-95. [CrossRef]

27. Mastrogiuseppe, M.; Poggiali, V.; Hayes, A.G.; Lunine, J.I.; Seu, R.; Mitri, G.; Lorenz, R.D. Deep and methane-rich lakes on Titan. Nat. Astron. 2019, 3, 535-542. [CrossRef]

28. Wye, L.C.; Zebker, H.A.; Lorenz, R.D. Smoothness of Titan's Ontario Lacus: Constraints from Cassini RADAR specular reflection data. Geophys. Res. Lett. 2009, 36, 16201. [CrossRef]

29. Zebker, H.; Hayes, A.; Janssen, M.; Le Gall, A.; Lorenz, R.; Wye, L. Surface of Ligeia Mare, Titan, from Cassini altimeter and radiometer analysis. Geophys. Res. Lett. 2014, 41, 308-313. [CrossRef]

30. Grima, C.; Mastrogiuseppe, M.; Hayes, A.G.; Wall, S.D.; Lorenz, R.D.; Hofgartner, J.D.; Stiles, B.C.; Elachi, C. The Cassini RADAR Team. Surface roughness of Titan's hydrocarbon seas. Earth Planet. Sci. Lett. 2017, 474, 20-24. [CrossRef]

31. Poggiali, V.; Mastrogiuseppe, M.; Hayes, A.G.; Seu, R.; Birch, S.P.D.; Lorenz, R.; Grima, C.; Hofgartner, J.D. Liquid-filled canyons on Titan. Geophys. Res. Lett. 2016, 43, 7887-7894. [CrossRef]

32. Lorenz, R.D. The flushing of Ligeia: Composition variations across Titan's seas in a simple hydrological model. Geophys. Res. Lett. 2014, 41, 5764-5770. [CrossRef]

33. Tan, S.P.; Kargel, J.S.; Jennings, D.E.; Mastrogiuseppe, M.; Adidharma, H.; Marion, G.M. Titan's liquids: Exotic behavior and its implications on global fluid circulation. Icarus 2015, 250, 64-75. [CrossRef]

34. Tokano, T.; Lorenz, R.D. Modeling of Seasonal Lake Level Fluctuations of Titan's Seas/Lakes. J. Geophys. Res. Planets 2019, 124, 617-635. [CrossRef]

35. Corlies, P.; Hayes, A.G.; Birch, S.P.D.; Lorenz, R.; Stiles, B.W.; Kirk, R.; Poggiali, V.; Zebker, H.; Iess, L. Titan's Topography and Shape at the End of the Cassini Mission. Geophys. Res. Lett. 2017, 44, 754-761. [CrossRef]

36. Poggiali, V.; Mastrogiuseppe, M.; Hayes, A.G.; Seu, R.; Mullen, J.P.; Birch, S.P.D.; Raguso, M.C. High-Resolution Topography of Titan adapting the Delay/Doppler Algorithm to the Cassini RADAR Altimeter Data. IEEE Trans. Geosci. Remote Sens. 2019. [CrossRef]

37. Hayes, A.; Aharonson, O.; Lunine, J.; Kirk, R.; Zebker, H.; Wye, L.; Lorenz, R.; Turtle, E.; Paillou, P.; Mitri, G.; et al. Transient surface liquid in Titan's polar regions from Cassini. Icarus 2011, 211, 655-671. [CrossRef]

38. Hofgartner, J.D.; Hayes, A.G.; Lunine, J.I.; Zebker, H.; Lorenz, R.D.; Malaska, M.J.; Mastrogiuseppe, M.; Notarnicola, C.; Soderblom, J.M. Titan's “Magic Islands”: Transient features in a hydrocarbon sea. Icarus 2016, 271, 338-349. [CrossRef]

39. Lunine, J.I.; Lorenz, R.D. Rivers, Lakes, Dunes, and Rain: Crustal Processes in Titan's Methane Cycle. Annu. Rev. Earth Planet. Sci. 2009, 37, 299-320. [CrossRef]

40. Thompson, W.; Squyres, S.W. Titan and other icy satellites: Dielectric properties of constituent materials and implications for radar sounding. Icarus 1990, 86, 336-354. [CrossRef] 
41. Picardi, G.; Seu, R.; Coradini, A.; Zampolini, E.; Ciaffone, A. Radar geomorphologic characterization of Titan. In Proceedings of the 92 International Conference on Rader, Brighton, UK, 12-13 October 1992; IET: London, UK, 1992; pp. 254-257.

42. Ori, G.; Marinangeli, L.; Baliva, A.; Bressan, M.; Strom, R. Dynamics of liquid on Titan surface. Planet. Space Sci. 1998, 46, 1417-1421. [CrossRef]

43. Campbell, D.B.; Black, G.J.; Carter, L.M.; Ostro, S.J. Radar Evidence for Liquid Surfaces on Titan. Science 2003, 302, 431-434. [CrossRef]

44. Birch, S.; Hayes, A.; Corlies, P.; Stofan, E.; Hofgartner, J.; Lopes, R.; Lorenz, R.; Lunine, J.; MacKenzie, S.; Malaska, M.; et al. Morphological evidence that Titan's southern hemisphere basins are paleoseas. Icarus 2018, 310, 140-148. [CrossRef]

45. Aharonson, O.; Hayes, A.G.; Lunine, J.I.; Lorenz, R.D.; Allison, M.D.; Elachi, C. An asymmetric distribution of lakes on Titan as a possible consequence of orbital forcing. Nat. Geosci. 2009, 2, 851-854. [CrossRef]

46. Hayes, A.G.; Wolf, A.S.; Aharonson, O.; Zebker, H.; Lorenz, R.; Kirk, R.L.; Paillou, P.; Lunine, J.; Wye, L.; Callahan, P.; et al. Bathymetry and absorptivity of Titan's Ontario Lacus. J. Geophys. Res. 2010, 115. [CrossRef]

47. Ventura, B.; Notarnicola, C.; Casarano, D.; Posa, F.; Hayes, A.G.; Wye, L. Electromagnetic models and inversion techniques for Titan's Ontario Lacus depth estimation from Cassini RADAR data. Icarus 2012, 221, 960-969. [CrossRef]

48. Cordier, D.; Mousis, O.; Lunine, J.I.; Lebonnois, S.; Rannou, P.; Lavvas, P.; Lobo, L.Q.; Ferreira, A.G.M. Titan's lakes chemical composition: Sources of uncertainties and variability. Planet. Space Sci. 2012, 61, 99-107. [CrossRef]

49. Cordier, D.; Mousis, O.; Lunine, J.I.; Lavvas, P.; Vuitton, V. An estimate of the chemical composition of titan's lakes. Astrophys. J. 2009, 707, 128-131. [CrossRef]

50. Mastrogiuseppe, M.; Hayes, A.; Poggiali, V.; Seu, R.; Lunine, J.I.; Hofgartner, J.D. Radar Sounding Using Cassini Altimeter: Waveform Modelling and Monte Carlo approach for Data Inversion of Observation of Titan's seas. IEEE Trans. Geosci. Remote Sens. 2016, 54, 5646-5656. [CrossRef]

51. Mitchell, K.L.; Barmatz, M.B.; Jamieson, C.S.; Lorenz, R.D.; Lunine, J.I. Laboratory measurements of cryogenic liquid alkane microwave absorptivity and implications for the composition of Ligeia Mare, Titan. Geophys. Res. Lett. 2015, 42, 1340-1345. [CrossRef]

52. Malaska, M.J.; Hodyss, R.; Lunine, J.I.; Hayes, A.G.; Hofgartner, J.D.; Hollyday, G.; Lorenz, R.D. Laboratory measurements of nitrogen dissolution in Titan lake fluids. Icarus 2017, 289, 94-105. [CrossRef]

53. Mastrogiuseppe, M.; Hayes, A.G.; Poggiali, V.; Lunine, J.I.; Lorenz, R.D.; Seu, R.; Le Gall, A.; Notarnicola, C.; Mitchell, K.L.; Malaska, M.; et al. Bathymetry and composition of Titan's Ontario Lacus derived from Monte Carlo-based waveform inversion of Cassini RADAR altimetry data. Icarus 2018, 300, 203-209. [CrossRef]

54. Raguso, M.C.; Mastrogiuseppe, M.; Seu, R.; Piazzo, L. Super Resolution and Interferences Suppression Technique Applied to SHARAD Data. In Proceedings of the 2018 5th IEEE International Workshop on Metrology for AeroSpace (MetroAeroSpace), Rome, Italy, 20-22 June 2018; pp. 242-246.

55. Raguso, M.C.; Piazzo, L.; Mastrogiuseppe, M.; Seu, R.; Orosei, R. Resolution Enhancement and Interference Suppression for Planetary Radar Sounders. In Proceedings of the 2018 26th European Signal Processing Conference (EUSIPCO), Rome, Italy, 3-7 September 2018; pp. 1212-1216.

56. Brown, R.H.; Soderblom, L.A.; Soderblom, J.M.; Clark, R.N.; Jaumann, R.; Barnes, J.W.; Sotin, C.; Buratti, B.; Baines, K.H.; Nicholson, P.D. The identification of liquid ethane in Titan's Ontario Lacus. Nature 2008, 454, 607-610. [CrossRef]

57. Wall, S.; Hayes, A.; Bristow, C.; Lorenz, R.; Stofan, E.; Lunine, J.; Le Gall, A.; Janssen, M.; Lopes, R.; Wye, L.; et al. Active shoreline of Ontario Lacus, Titan: A morphological study of the lake and its surroundings. Geophys. Res. Lett. 2010, 37. [CrossRef]

58. Cornet, T.; Bourgeois, O.; Le Mouélic, S.; Rodriguez, S.; Lopez Gonzalez, T.; Sotin, C.; Tobie, G.; Fleurant, C.; Barnes, J.W.; Brown, R.H. Geomorphological significance of Ontario Lacus on Titan: Integrated interpretation of Cassini VIMS, ISS and RADAR data and comparison with the Etosha Pan (Namibia). Icarus 2012, 218, 788-806. [CrossRef]

59. Mitri, G.; Coustenis, A.; Fanchini, G.; Hayes, A.G.; Iess, L.; Khurana, K.; Lebreton, J.-P.; Lopes, R.M.; Lorenz, R.D.; Meriggiola, R.; et al. The exploration of Titan with an orbiter and a lake probe. Planet. Space Sci. 2014, 104, 78-92. [CrossRef] 
60. Lorenz, R.D.; Oleson, S.R.; Colozza, A.J.; Jones, R.; Packard, T.; Hartwig, J.; Newman, J.M.; Gyekenyesi, J.Z.; Schmitz, P.; Walsh, J. Exploring Titan's cryogenic hydrocarbon seas with boat-deployed expendable dropsondes. Adv. Space Res. 2018, 62, 912-920. [CrossRef]

61. Coradini, A.; Cramarossa, R.; Lombardo, P.; Picardi, G.; Seu, R. Topographic mapping of the moon via a radar system. EARSeL 1995, 4, 67-75.

62. Hensley, S.; Shaffer, S. Repeat pass radar observations of Venus from the Magellan Radar System. In Proceedings of the Lunar and Planetary Science Conference, Woodlands, TX, USA, 1-5 March 2010.

63. Iess, L.; Jacobson, R.A.; Ducci, M.; Stevenson, D.J.; Lunine, J.I.; Armstrong, J.W.; Asmar, S.W.; Racioppa, P.; Rappaport, N.J.; Tortora, P. The tides of Titan. Science 2012, 337, 457. [CrossRef]

64. Lorenz, R.D.; Stiles, B.W.; Kirk, R.L.; Allison, M.D.; del Marmo, P.P.; Iess, L.; Lunine, J.I.; Ostro, S.J.; Hensley, S. Titan's rotation reveals an internal ocean and changing zonal winds. Science 2008, 319, 1649-1651. [CrossRef]

65. Bills, B.G.; Nimmo, F. Rotational dynamics and internal structure of Titan. Icarus 2011, 214, 351-355. [CrossRef]

66. Tobie, G.; Lunine, J.I.; Sotin, C. Episodic outgassing as the origin of atmospheric methane on Titan. Nature 2006, 440, 61-64. [CrossRef]

67. Lunine, J.I. Saturn's Titan: A Strict Test for Life's Cosmic Ubiquity. Proc. Am. Philos. Soc. 2009, 153, $403-418$.

68. Lorenz, R.D.; Lunine, J.I.; McKay, C.P. Titan under a red giant sun: A new kind of "habitable" moon. Geophys. Res. Lett. 1997, 24, 2905-2908. [CrossRef]

69. Hemingway, D.; Nimmo, F.; Zebker, H.; Iess, L. A rigid and weathered ice shell on Titan. Nature 2013, 500, 550-552. [CrossRef]

70. Beghin, C.; Sotin, C.; Hemelin, M. Titan's native ocean revealed beneath some $45 \mathrm{~km}$ of ice by Schumann-like resonance. C. R. Geosci. 2010, 342, 425-433. [CrossRef]

71. Picardi, G.; Plaut, J.J.; Biccari, D.; Bombaci, O.; Calabrese, D.; Cartacci, M.; Cicchetti, A.; Clifford, S.M.; Edenhofer, P.; Farrell, W.M.; et al. Radar Soundings of the Subsurface of Mars. Science 2005, 310, 1925. [CrossRef]

72. Seu, R.; Phillips, R.J.; Biccari, D.; Orosei, R.; Masdea, A.; Picardi, G.; Safaeinili, A.; Campbell, B.A.; Plaut, J.J.; Marinangeli, L.; et al. SHARAD sounding radar on the Mars Reconnaissance Orbiter. J. Geophys. Res. Space Phys. 2007, 112, 5. [CrossRef]

73. Notaro, V.; Durante, D.; Iess, L. On the determination of Jupiter's satellite-dependent Love numbers from Juno gravity data. Planet. Space Sci. 2019, 175, 34-40. [CrossRef]

74. Mitri, G.; Meriggiola, R.; Hayes, A.; Lefèvre, A.; Tobie, G.; Genova, A.; Lunine, J.I.; Zebker, H. Shape, topography, gravity anomalies and tidal deformation of Titan. Icarus 2014, 236, 169-177. [CrossRef]

75. Sagan, C.; Dermott, S.F. The tide in the seas of Titan. Nature 1982, 300, 731-733. [CrossRef]

76. Tokano, T. Simulation of tides in hydrocarbon lakes on Saturn's moon Titan. Ocean Dyn. 2010, 60, 803-817. [CrossRef]

77. Lorenz, R. Winds and tides of Ligeia Mare, with application to the drift of the proposed time TiME (Titan Mare Explorer) capsule. Planet. Space Sci. 2012, 60, 72-85. [CrossRef]

78. Vincent, D.; Karatekin, Ö.; Vallaeys, V.; Hayes, A.G.; Mastrogiuseppe, M.; Notarnicola, C.; Dehant, V.; Deleersnijder, E. Numerical study of tides in Ontario Lacus, a hydrocarbon lake on the surface of the Saturnian moon Titan. Ocean Dyn. 2016, 66, 461-482. [CrossRef]

79. Sotin, C.; Barnes, J.W.; Lawrence, K.J.; Soderblom, J.M.; Audi, E.; Brown, R.H.; Le Mouelic, S.; Baines, K.H.; Buratti, B.J.; Clark, R.N.; et al. Bright, tidal currents between Titan's seas detected by solar glints. In Proceedings of the AGU Fall Meeting Abstracts, San Francisco, CA, USA, 14-18 December 2015. Abstruct P12B-04.

80. Hayes, A.G. The Lakes and Seas of Titan. Annu. Rev. Earth Planet. Sci. 2016, 44, 57-83. [CrossRef]

81. Wahr, J.M.; Zuber, M.T.; Smith, D.E.; Lunine, J.I. Tides on Europa, and the thickness of Europa's icy shell. J. Geophys. Res. 2006, 111, E12005. [CrossRef]

82. Zieger, A.R.; Hancock, D.W.; Hayne, G.S.; Purdy, C.L. NASA Radar Altimeter for the TOPEX/POSEIDON Project. Proc. IEEE 1991, 79, 810-826. [CrossRef]

83. Egbert, G.D.; Bennett, A.F.; Foreman, M.G.G. TOPEX/POSEIDON tides estimated using a global inverse model. J. Geophys. Res. Space Phys. 1994, 99, 24821. [CrossRef] 
84. Shum, C.K.; Woodworth, P.L.; Andersen, O.B.; Egbert, G.D.; Francis, O.; King, C.; Klosko, S.M.; Le Provost, C.; Li, X.; Molines, J.M.; et al. Accuracy Assessment of Recent Ocean Tide Models. J. Geophys. Res. 1997, 102, 173-194. [CrossRef]

85. Wagner, C.A. A Refined M2, Tide from GEOSAT Altimetry; NOAA Technical Report NOS 136 NGS 48; NOAA: Silver Spring, MD, USA, 1991.

86. Carter, L.M.; Campbell, B.A.; Holt, J.W.; Phillips, R.J.; Putzig, N.E.; Mattei, S.; Seu, R.; Okubo, C.H.; Egan, A.F. Dielectric properties of lava flows west of Ascraeus Mons, Mars. Geophys. Res. Lett. 2009, 36. [CrossRef]

87. Campbell, B.; Carter, L.; Phillips, R.; Plaut, J.; Putzig, N.; Safaeinili, A.; Seu, R.; Biccari, D.; Egan, A.; Orosei, R. SHARAD radar sounding of the Vastitas Borealis Formation in Amazonis Planitia. J. Geophys. Res. Space Phys. 2008, 113. [CrossRef]

88. Campbell, B.A.; Morgan, G.A. Fine-Scale Layering of Mars Polar Deposits and Signatures of Ice Content in Nonpolar Material From Multiband SHARAD Data Processing. Geophys. Res. Lett. 2018, 45, 1759-1766. [CrossRef]

89. Le Gall, A.; Malaska, M.; Lorenz, R.; Janssen, M.; Tokano, T.; Hayes, A.; Mastrogiuseppe, M.; Lunine, J.; Veyssière, G.; Encrenaz, P.; et al. Composition, seasonal change, and bathymetry of Ligeia Mare, Titan, derived from its microwave thermal emission. J. Geophys. Res. Planets 2016, 121, 233-251. [CrossRef]

90. Janssen, M.; Le Gall, A.; Lopes, R.; Lorenz, R.; Malaska, M.; Hayes, A.; Neish, C.; Solomonidou, A.; Mitchell, K.; Radebaugh, J.; et al. Titan's surface at $2.18-\mathrm{cm}$ wavelength imaged by the Cassini RADAR radiometer: Results and interpretations through the first ten years of observation. Icarus 2016, 270, 443-459. [CrossRef]

91. Zhang, Z.; Hagfors, T.; Nielsen, E.; Picardi, G.; Mesdea, A.; Plaut, J.J. Dielectric properties of the Martian south polar layered deposits: MARSIS data inversion using Bayesian inference and genetic algorithm. J. Geophys. Res. Planets 2008, 113, 5004. [CrossRef]

92. Bucciarelli, T.; Cacopardi, S.; Picardi, G.; Seu, R.; Levrini, G.; Perfetti, R. Tracking algorithms in radar altimetry. In Proceedings of the International Geoscience and Remote Sensing Symposium, Edinburgh, UK, 12-16 September 1988; pp. 973-976.

93. Lopes, R.M.C.; Wall, S.D.; Elachi, C.; Birch, S.P.D.; Corlies, P.; Coustenis, A.; Hayes, A.G.; Hofgartner, J.D.; Janssen, M.A.; Kirk, R.L.; et al. Titan as Revealed by the Cassini Radar. Space Sci. Rev. 2019, $215,33$. [CrossRef]

94. Nixon, C.; Lorenz, R.; Achterberg, R.; Buch, A.; Coll, P.; Clark, R.; Courtin, R.; Hayes, A.; Iess, L.; Johnson, R.; et al. Titan's cold case files-Outstanding questions after Cassini-Huygens. Planet. Space Sci. 2018, 155, 50-72. [CrossRef]

95. Bruzzone, L.; Plaut, J.J.; Alberti, G.; Blankenship, D.D.; Bovolo, F.; Campbell, B.A.; Ferro, A.; Gim, Y.; Kofman, W.; Komatsu, G.; et al. RIME: Radar for icy moon exploration. In Proceedings of the IEEE IGARSS, Melbourne, Australia, 13-18 July 2013; pp. 3907-3910. [CrossRef]

96. Sambuelli, L.; Bava, S. Case study: A GPR survey on a morainic lake in northern Italy for bathymetry, water volume and sediment characterization. J. Appl. Geophys. 2012, 81, 48-56. [CrossRef]

(C) 2019 by the author. Licensee MDPI, Basel, Switzerland. This article is an open access article distributed under the terms and conditions of the Creative Commons Attribution (CC BY) license (http://creativecommons.org/licenses/by/4.0/). 